\title{
Geminate blockage in Logoori harmony with no added machinery
}

\author{
David Odden \\ Ohio State University \\ david.odden@gmail.com ORCID: https://orcid.org/0000-0002-6743-0684
}

\begin{abstract}
Submitted: 15/07/2019; Accepted: 05/10/2019; Published online: 17/06/2020
Citation / Cómo citar este artículo: David Odden. (2019). Geminate blockage in Logoori harmony with no added machinery. Loquens, 6(2), e064. https://doi.org/10.3989/loquens.2019.064

ABSTRACT: Following the demise of the SPE theory of phonology, little attention was paid to how rules should be formulated. Instead, there was a general trend to minimize the language-specific component of a grammar, to factor out recurring patterns and state them as independent constraints or parameters. The richer representations of autosegmental phonology additionally led to uncertainty in rule formulation, primarily because of questions about what the correct representations are, but also because specifying dominance and precedence relations is more complex than just specifying precedence relations.
\end{abstract}

\begin{abstract}
This paper discusses a vowel harmony rule in the Bantu language Logoori, which is blocked by an intervening geminate consonant. It is typologically surprising that an intervening geminate has an effect on harmony, and there is no clear model for how such an effect in a rule should be encoded. It is shown that the effect follows naturally from correctly formalizing the rule, with attention to how rule and representational substrings are matched, and no ruleexternal conditions on the rule are necessary.
\end{abstract}

Keywords: Harmony, formalism, rule, geminates, adjacency.

RESUMEN: Análisis sin mecanismos complementarios del bloqueo de la armonía mediante geminadas en Logoori. A partir del declive de la teoría fonológica de $S P E$, se prestó poca atención a cómo se deberían formular las reglas. Existía, en cambio, una tendencia general a minimizar el componente gramatical específico de una lengua para factorizar los patrones recurrentes y establecerlos como restricciones o parámetros independientes. Las representaciones, más ricas, de la fonología autosegmental generaron además dudas sobre cuál había de ser la formulación de reglas, principalmente por los interrogantes surgidos acerca de cómo son las correctas representaciones, pero también porque especificar las relaciones de dominancia y de precedencia resulta más complejo que especificar simplemente las relaciones de precedencia.

En este artículo se discute una regla de armonía vocálica de la lengua bantú Logoori, que se ve bloqueada al intervenir una consonante geminada. Desde un punto de vista tipológico es sorprendente que una geminada interviniente afecte a la armonía, y no se cuenta con un modelo claro sobre cómo debe codificarse dicho efecto en una regla. Aquí se muestra que el efecto se desprende naturalmente de la formalización correcta de la regla, atendiendo a cómo se corresponden la regla y las subcadenas representacionales, y que no se precisan condiciones sobre la regla externas a ella.

Palabras clave: Armonía, formalismo, regla, geminada, adyacencia.

\section{INTRODUCTION}

In early generative phonology, exemplified by $S P E$ (Chomsky \& Halle, 1968), phonological rules were formalized according to a specific theory of rules and an associated algorithm for matching rules to strings. The predominant practice was that rule statements would explicitly encode whatever the relevant factual generalizations are within the rule, given a theory of rule formalism. This was not particularly difficult to do, since

Copyright: (C) 2019 CSIC. This is an open-access article distributed under the terms of the Creative Commons Attribution 4.0 International (CC BY 4.0) License. 
the theory of rule formalization adopted at the time had a wide range of expressive devices, such as parentheses, braces, feature variables and so on, which allowed virtually any statable condition to be expressed in a rule.

In the post-SPE era, the practice of fully formalizing rules fell into desuetude, especially with the rise of strong substantive concepts in Universal Grammar, concepts such as markedness, structure preservation, surface constraints, and other aspects of rule operation, where various aspects of a rule's actions could be removed from the formal statement of the rule, and stated separately: the classical example is feature-identity conditions, which might be expresed via an independent device, the Obligatory Contour Principle.

The SPE theory of rule formulation was founded on a very straightforward theory of simple rules, and a highly contentious system of rule schemata which abbreviated potentially infinite sets of simple rules into a single compact metarule expression. The vast majority of such rule schemata were not well-motivated, and ultimately with the rise of autosegmental representations, all of the $S P E$ abbreviatory devices could either be dispensed with entirely with no loss of generality (e.g. the double slashdash notation, bar-in-box notation), or were rendered unnecessary given certain premises about representation.

Because so much of the SPE theory of rules was embodied in the ultimately discredited notion of rule schema, a natural reaction to rule formalism was that formalizing rules was a triviality, and it was widely felt that "if the representations are right, then the rules will follow" (McCarthy, 1988, p. 84). Because of the over-optimistic view that a theory of rule statement might be unnecessary as long as we have a good theory of representations, questions of how to formalize autosegmental rules did not receive the attention that they properly require.

The purpose of this paper is to present and analyze a fact pattern from the phonology of the Bantu language Logoori, and to demonstrate a fact about phonological analysis that should be self-evident, which is that precise rule formulation matters. The fact of interest is that the language has a leftward vowel height harmony rule, which does not apply across a geminate consonant. The question for phonological theory is: how is this fact encoded in the grammar? ${ }^{1}$

Section 2 briefly reviews theories of geminates and identify-reference: there may be something in the nature of geminates that provides a solution. Section 3 presents the relevant facts of Logoori. Section 4 evaluates various means of stating the harmony rule, including the blocking effect of geminates. Many theories of geminates and

\footnotetext{
1 There is one analogous claim in the literature regarding Yucatec Mayan (Krämer n.d., 2001), claimed to exemplify a moraic adjacency requirement in vowel harmony - this is the fact of interest in Logoori. This analysis is not discussed here for two reasons. First, it is unclear how compelling the case is in Yucatec. Butler (2005) points out (and Bohnemeyer, p.c., confirms) that the phonological contention is questionable. Butler argues that what blocks harmony is an intervening morpheme, not an intervening mora. Second, Krämer's account is framed in OT, and the mechanisms proposed vary substantially across versions of the analysis. There is no contradiction between Krämer's factual claim and the framework proposed here, but it is impossible to find a formal parallelism between the OT account and the present rulebased account.
}

identity references can encode this effect, but all save one of these accounts require the addition of otherwise unnecessary computational devices. The one exception is, simply, that a geminate consonant is in fact "moraic", which is uncontroversial. A very simple statement of the harmony rule is that the relevant vowel height feature spreads from one moraic vowel to the preceding. The formal conditions for applying this rule are lacking when a geminate stands between the target and trigger vowels.

The analysis will be carried out within a substance-free version of Formal Phonology (FP), see Odden (2013). The fundamental principle that will be invoked from that theory is conceptual economy: every thing which is claimed to exist must be justified, both for claims of general grammatical theory, and for claims about a particular rule in a particular language. Adding theoretical devices always requires justification even if the devices are attributed to Universal Grammar, and making do with fewer theoretical resources is always a virtue.

\section{GEMINATES AND IDENTICAL CONSONANTS}

Geminate consonants have been treated extensively in the history in generative phonology (Davis, 2011; see Odden, 2011a, for discussion of analogous issues in vowel length). Treatments of geminates include segmental accounts (one consonant with a length feature; two adjacent identical consonants) and suprasegmental accounts (one consonant segment with a distinguishing suprasegmental property, such as a mora).

Two questions regarding the treatment of geminates in a grammar are: first, what is their representation, and second, how do rules in the grammar identify them? The first subsection addresses the former issue and the second addresses the rule-reference question.

\subsection{Representations of geminates}

Prior to the advent of Autosegmental Phonology, generative phonology had two representations for geminates: they are single segments with a feature [+long], or they are sequences of two identical consonants. See Pyle (1971) and Kenstowicz \& Pyle (1973) for more details. There were advantages and disadvantages to both positions. The single-segment theory explains why geminates resist separation by rules that insert vowels into consonant clusters, and the cluster theory explains why they behave like other $\mathrm{CC}$ sequences in conditioning vowel shortening.

In non-linear theories of representation, geminates are typically represented as a single segment with a special suprasegmental property. This might be two "skeletal" positions, as proposed in McCarthy (1979), Leben (1980), Clements \& Keyser (1983) and elsewhere. Or, it might be the fact of being associated to a mora, as proposed in Hayes (1989), Davis (1994), Morén (1999) and others.

It is important to bear in mind that multiple representations for geminates are not theoretically precluded, especially in an FP account. FP does not make substantive dictates, to the effect that there can only be a single 
analysis of a particular phenomenon, indeed "phenomenon" is not a construct of grammatical theory in FP. It is possible, for example, that geminates are identical clusters in some contexts and single prosodically-distinguished segments in other contexts. Indeed, this possibility was both recognized and empirically justified in autosegmental accounts of geminates, which distinguished between "fake geminates" (bisegmental clusters) and "true geminates" (prosodically-distinguished single segments).

\subsection{OCP and identity in rules}

Referring to the facts presented in subsequent sections, there are three reasons to be concerned with identity references in Logoori phonology. One is that vowels delete, given certain conditions which appear to include (partial) identity of the surrounding consonants; secondly, such deletion creates geminates; and finally, geminates block vowel harmony. Apart from the question of how geminates are represented in a language, there is also the question of how identical consonants are identified in a rule system. For example, if geminates are moraic single consonants, that fact could be encoded in a rule to account for one subset of apparent identity references - any rule identifying an identical consonant sequence in the output could do so by referring to the presence of a moraic consonant. Many other identity references could not be subsumed under this mechanism (e.g. when two nonadjacent consonants are required to be non-identical or to be identical - the antigemination and anti-antigemination effects). See Odden (2013, sec. 4.6) for further discussion of theories of identity reference in rules.

Feature variable notation (Chomsky \& Halle, 1968) is the most powerful tool for identifying geminates in a rule. In that theory, a geminate is a sequence $\left[\alpha \mathrm{F}_{1}, \beta \mathrm{F}_{2}, \gamma \mathrm{F}_{3} \ldots\right]$ $\left[\alpha F_{1}, \beta F_{2}, \gamma F_{3} \ldots\right]$, where sufficient features are specified to distinguish geminates from other clusters. This Value Variable theory posits that Greek letters function as independent variables, just as $i, j, k$ are mathematical variables. An alternative theory, first suggested in McCawley (1974) and developed in Odden (2013) where it is termed Identical Value theory, is that values are not abstractable from the features which they are values of, instead "same in value" is a possible attribute of a node mentioned in rules, alongside "+" and "-". Thus a rule can specify [+nasal], [-nasal] or [=nasal], the latter interpretable only if there is some other segment whose value of nasality is being compared. ${ }^{2}$ Likewise, when two nonterminal representational nodes $\mathrm{N}$ are subject to an identity condition,

2 See Reiss (2003) for a formal interpretation of identify references as conditions on rules using quantifiers. Identical Value theory, as discussed in Odden (2013), does not entail a specific formal implementation of how identify references are made, and is consistent with modified SPE rule formulation as well as autosegmental rule formulation, and is equally applicable to privative theories of features. The identify relation $"=\mathrm{X} . .=\mathrm{X}$ ", or its negation, $" \neg(=\mathrm{X} \ldots=\mathrm{X})$ " is a condition imposed on the representation which constitutes the structural description of a rule: a concise standardized notation that expresses such a condition has not been developed. the condition is satisfied if all nodes dominated by N satisfy the identity requirement. Since Identical Value theory does not separate variables from the features they are attributes of, expressions such as [aback, around] are impossible - a positive result since they are also unmotivated.

If a rule only applies before a geminate, that property may be encoded as looking for a sequence $\left[=\mathrm{F}_{1},=\mathrm{F}_{2}\right.$, $\left.=\mathrm{F}_{3} \ldots\right]\left[=\mathrm{F}_{1},=\mathrm{F}_{2},=\mathrm{F}_{3} \ldots\right]$, or more generally $[=\mathrm{R}][=\mathrm{R}]$, where $\mathrm{R}$ is the segmental root node which dominates all segmental features. Insofar as there is no justification for generalized variables coming from expressions of the type $\left[\alpha F_{1}\right]\left[\alpha F_{2}\right]$ (the value of one feature must be the same as that of a different feature), Identical Value theory is the simplest and more restricted means of comparing the featural similarity of two segments: that theory does not make unsupported claims. Value Variable theory lacks empirical support in that exact realm where the two theories are distinguishable, and until evidence for generalized variables is adduced, the more limited claim that rules can encode the concept "same" stands as the only linguistically justified claim.

A different means of encoding identity references has been applied in certain examples, by referring to a hypothesized component of some grammatical theories, the Obligatory Contour Principle (OCP), which prohibits adjacent identical segments. As exemplified by McCarthy (1986), reference to the identity of segments can be partially simulated by reference to the fact that a contravention of the OCP does or potentially exists, and this fact could control whether a given rule applies. This logic is used to prevent syncope in Syrian Arabic from applying when the preceding and following consonants are identical. Thus /btəskon-i/ $\rightarrow$ [btəskni] 'you (f.s.) dwell' (cf. [btəskon] 'you (m.s.) dwell', but syncope is blocked in [bisabbəbu] 'they cause', because the relevant vowel is surrounded by identical consonants. The essential idea is that the rule is blocked just in case applying the rule would violate the OCP.

See Odden (1988) for discussion of this theory: the fundamental problem with the theory is that it is insufficient, since, empirically, identity references are not limited to preventing rule application from making identical consonants adjacent, then can also apply only if doing so creates an OCP violation ("antiantigemination"). Baković (2005) further analyzes this problem within Optimality Theory, proposing a means of deriving the antiantigemination effect. The specific OT mechanisms proposed by Baković do not translate into a rule-based means of capturing the geminate blockage effect, ${ }^{3}$ but as we will see, the generalization could in principle be expressed by reference to a violation of the OCP within the string being scanned for harmony.

\footnotetext{
3 This paper will not pursue an OT-theoretic account of the problem, since constructing such an account would take us too far afield. The central question is how the condition is encoded in an FP-consistent theory of computations, which entails that there be a theory of rule (or constraint) statement, and so far, there is no theory of constraint formalization.
} 
In short, there are ample formal means to identify the fact that a geminate exists: it may be identified structurally, either as a segment associated to a mora, as one associated to two suprasegmental positions, by specifying that the sequence contains identical feature values, or possibly by some reference to the OCP. Each method of recognizing geminates in a rule has theoretical prerequisites. If it is because of their unique representation (single segments occupying two prosodic positions), geminates (at least some geminates) must be single segments, and there must be two representational levels rather than a single unified feature matrix. If it is because geminates associate to a mora, then there must be moras. If rules refer to geminates via an autonomous constraint OCP, then the OCP must exist, and rules must have some means of referring to such a constraint. Whatever the existential claims are of the particular analysis, those claims require prior justification, and evaluation of the evidence for the device forms the basis for selecting the correct analysis.

\section{THE FACTS OF LOGOORI}

Logoori is a Bantu language of the Luhya subgroup, spoken in Western Kenya. Four main rules are relevant: two vowel-deletion rules which feed into an assimilation rule, creating geminate consonants (section 3.1), plus a vowel height harmony rule (section 3.2). The former rules create the geminate consonants which block vowel harmony, as discussed in 3.3.

The segmental inventory of Logoori includes the vowels [i i e a o $v \mathrm{u}$ ] and the consonants [p t t $\int \mathrm{k} \mathrm{b} d \mathrm{~d} 3 \mathrm{~g} \mathrm{~m} \mathrm{n}$ $\mathrm{n} \mathrm{n} \mathrm{r} \mathrm{fs} \int \mathrm{hvzj}$ w]. Consonants will be represented orthographically, where $<\operatorname{ch} \mathrm{j}$ n ny $>$ are equivalent to IPA $\left[\mathrm{t} \int \mathrm{d} 3\right.$ $\mathrm{n}$ nj]. Vowel length is phonologically significant (indicated by doubling the vowel), and $\mathrm{H}$ tone (marked with acute accent) contrasts with $\mathrm{L}$ (unmarked, except that $\mathrm{L}$ toned moraic consonants bear grave accent). Allophonically, [11] appears when geminate $r r$ would be expected.

\subsection{Vowel deletion}

Geminate consonants result from applying one of two vowel deletion rules. The first rule applies to a high vowel which is preceded by $/ \mathrm{r} /$ and followed by a coronal non-fricative. The second rule applies to high vowels that appear in the sequence / $/ v_{-} \mathrm{v} /$ (between voiced labial fricatives). These deletions take place between roughly homorganic consonants, and the deletions could be seen as part of a grander typology of OCP effects. Both rules are optional, though they are usually applied. Deletion before coronals is considered first.

\subsubsection{Deletion before coronals}

Logoori has a noun class system where all nouns are assigned to one of 15 classes, indicated by a prefix on nouns. Verbs also bear appropriate subject and object prefixes indicating class of a nominal referent. The two class markers of interest for pre-coronal deletion are /ri/ 'Class
5' and /ro/ 'Class 11'. Examples of these prefixes on nouns, attesting the optional deletion of the prefix vowel, are seen below. When the class prefix vowel is deleted, the resulting consonant cluster surfaces as a geminate. Nouns also have a word-initial secondary agreement marker composed of a vowel, /I/ in Class 5 and / $/$ / in Class 11.

\begin{tabular}{|c|c|}
\hline I-rí-kuuré & 'owl' \\
\hline I-ri-gina & 'stone' \\
\hline U-ru-bááho & 'lumber' \\
\hline ひ-rひ-gága & 'fence' \\
\hline I-ri-díku, I-d-díku & 'day' \\
\hline I-ri-néke, I-n-néke & 'herb sp.' \\
\hline I-ri-tímu, i-t-tímu & 'spear' \\
\hline I-ri-jaambi, I-j-jaambi & 'mat' \\
\hline I-ri-nonyi, I-n-jonyi & 'bird' \\
\hline 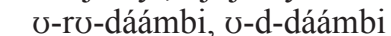 & 'wick' \\
\hline ひ-ro-távati, $\mho$-t-távati & 'plant sp \\
\hline
\end{tabular}

Adjectives undergo vowel deletion and gemination as well. ${ }^{4}$

(2) ri-táámbi, t-táámbi ro-táámbi, t-táámbi

' $\operatorname{long}_{5} '$,
'long
11

Object prefixes on verbs undergo this process as well. ${ }^{5}$

(3) ku-rí-karaanga

kv-rú-mana

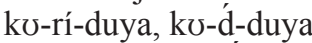

ku-rú-duya, ku-d-duya

ku-rí-taaga, kǔ-t-taaga

ku-rú-chaba, kǔ-c-chaba

ku-rú-nava, ku-ń-nava

ku-rú-naga, ku-ń-naga

ku-rú-sava, *kussava

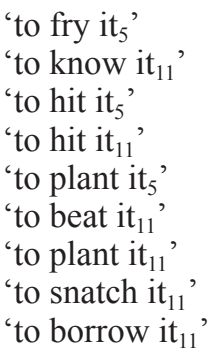

In addition, when reduction takes place before $/ \mathrm{r} /$, the result is [11]: [r] and [11] are in complementary distribution in Logoori, ${ }^{6}$ with [11] appearing when geminate and [r] appearing otherwise.

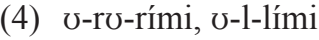

I-ri-ráánde, I-1-láánde

I-ri-roungo, I-1-loongo

ro-róúngi

ri-rúớngi

1-lứóngi

$$
\begin{aligned}
& \text { 'tongue' } \\
& \text { 'plant sp.' } \\
& \text { 'rafter' } \\
& \text { 'straight, } \\
& \text { 'straight,' } \\
& \text { 'straight } \\
& 5,11
\end{aligned}
$$

\footnotetext{
4 Subscripted numerals refer to the noun Class of the referent, thus ' long $_{5}$ ' means 'long, referring to some thing in $\mathrm{Cl}$. 5 '

5 The object prefix has $\mathrm{H}$ tone, which transfers to the voiced consonant corresponding to $/ \mathrm{r} / \mathrm{under}$ vowel deletion, e.g. [kudduya], and the $\mathrm{F}_{0}$ peak occurs during the stop. When that consonant is voiceless, tone cannot be phonetically manifested in [t], but there is still an audible rapid rise with the peak at the end of [v] in [kǔttaaga]. There is no evidence showing whether $\mathrm{H}$ tone is phonologically transferred to the preceding vowel as a contour tone, or, alternatively, the phonological output may be [kottaaga] and phonetic rise is due to a phonetic rule. 6 The name of the language in Logoori is [1lógoori].
} 
Geminate blockage in Logoori harmony with no added machinery $\bullet 5$
kv-rú-rında
kv-rí-runda
kv-1́-lında

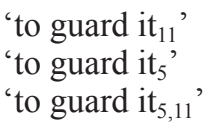

Reduction and gemination do not apply before fricatives, hence we find only [ku-rú-sava] (*[kussava]) 'to borrow it ${ }_{11}$ ', [ku-rí-zugaanya] (*[kuzzugaanya]) 'to mix it $_{5}$ '. Reduction only affects underlying high vowels, not /a/ as encountered in the immediate future prefix $/ \mathrm{ra} / \mathrm{in}$ [a-ra-dééka] (*[addééka]) 'he will cook'.

\subsubsection{Deletion between labials}

High vowels likewise delete optionally when simultaneously preceded and followed by $/ \mathrm{v} /$. The relevant prefixes which attest this rule are /vi/ 'Class 8' and /vo/ 'Class 14'.

(5)

\begin{tabular}{|c|c|}
\hline vi-vára, & \\
\hline I-vi-VwÍ, I-V-Vwí & \\
\hline v-vá!r & \\
\hline U-vण- & \\
\hline jállú, & \\
\hline V-vísi & $W_{14}$ \\
\hline
\end{tabular}

These morphemes, functioning as object and subject prefixes, also undergo vowel deletion in verbs.

(6) ku-ví-variza, ku-v́-variza ku-vú-variza, ku-v́-variza vi-vaazwí, v-vaazwí vu-vaazwí, v-vaazwí

$$
\begin{aligned}
& \text { 'to count them,' } \\
& \text { 'to count } \mathrm{it}_{14}, \\
& \text { 'it }{ }_{8} \text { was carved' } \\
& \text { 'they }{ }_{14} \text { were carved' }
\end{aligned}
$$

The vowel /a/ does not delete in an analogous context, cf. [a-va-vứ'gúsứ] (*[avvớ gúsứ]) 'Bukusus'. There is also no deletion of the vowel in /vi, vo/ before other labials, thus only [I-ví-'fóóyó] 'rabbits', and not imaginable variants like *[Ivfooyo, Iffooyo, IVvooyo].

\subsection{Height harmony}

When a lax high vowel is followed in the next syllable by a mid vowel, the high vowel optionally (but almost always) becomes mid. This rule iterates throughout the word.

In addition to the class prefixes /vv-/, /rv-/ previously discussed, height harmony applies to the prefixes $/ \mathrm{kI}-/$ 'Class 7' and the infinitive prefix / $\mathrm{kv}-/$.

(7) I-kí-'diíndí

I-kí-sáású

I-kI-búúsi

é-ké-'mérwá

e-ke-bóóko

e-ke-déte

v-rú-tu

U-ro-távati

\begin{tabular}{|c|c|}
\hline ひ-vひ-hıında & 'riches' \\
\hline U-vú-ráhi & 'goodness' \\
\hline o-vó-gére & 'leoprosy' \\
\hline o-vó-gó yáánứ & 'confusion' \\
\hline kv-kína & 'to play' \\
\hline ku-káraanga & 'to fry' \\
\hline ko-téma & 'to chop' \\
\hline ko-déeka & 'to cook' \\
\hline ko-moroma & 'to talk' \\
\hline
\end{tabular}

o-ro-geembe

o-ro-vóni

'drum'
'splinter'
'cat'
'plant'
'whip'
'finger'
'frog'
'plant sp.'
'razor'
'jealousy'

In inflected verbs, these class prefixes functioning as subject markers harmonize, as do the subject prefixes $/ \mho-/$ '2s', /I-/ 'Class 9', /ku-/ '1p'.
(8) U-karwi

I-karwi

ku-kubwi

kI-kobwi

ru-kobwi

vo-kubwi

o-rórwí

e-rórwí

ko-rórwí

ke-rórwí

ro-rórwí

vo-rórwí

\author{
' 2 s were cut' \\ 'it ${ }_{9}$ was cut' \\ 'we were beaten' \\ 'it 7 was beaten' \\ ' $\mathrm{it}_{11}$ was beaten' \\ 'it ${ }_{14}$ was beaten' \\ '2s were seen' \\ 'it $t_{9}$ was seen' \\ 'we were seen' \\ 'it 7 was seen' \\ 'it 7 was seen' \\ 'it ${ }_{14}$ was seen'
}

Likewise, object prefixes including /gI-/ 'Class 9' and /I-/ 'reflexive' harmonize.

(9) ara-kú-holla

ara-kí-holla

ara-gí-holla

ara-rú-holla

ara-vú-holla

ar-î́-holla

ara-kó-reeta

ara-ké-reeta

ara-gé-reeta

ara-ró-reeta

ara-vó-reeta

ar-éé-reeta

\author{
'he will hear us' \\ 'he will hear it 7 ', \\ 'he will hear it,' \\ 'he will hear it ${ }_{11}$ ', \\ 'he will hear it ${ }_{14}$ ' \\ 'he will hear himself' \\ 'he will bring us' \\ 'he will bring it ${ }_{7}$ ' \\ 'he will bring it ${ }_{9}$ ' \\ 'he will bring it ${ }_{11}$ ' \\ 'he will bring it ${ }_{14}$ ' \\ 'he will bring himself'
}

Finally, the tense-aspect prefix /-kI-/ 'persistive' harmonizes.
(10) a-kI-kina
a-kI-vaka
a-ki-kúúta
a-ke-hoomá
a-ke-géénda

Alternative forms such as [arakíreeta] 'he will bring it, ${ }_{7}$ are also attested.

\footnotetext{
7 No grammatical significance is imputed to the fact that harmony is nearly always applied, but gemination-reduction applies perhaps $50 \%$ of
} the time. 
One contextual restriction on harmony is that it does not apply to a tense high vowel, as demonstrated with examples of the prefixes /ri/ 'Class 5', /zi/ 'Class 10', / vi/ 'Class 8'.

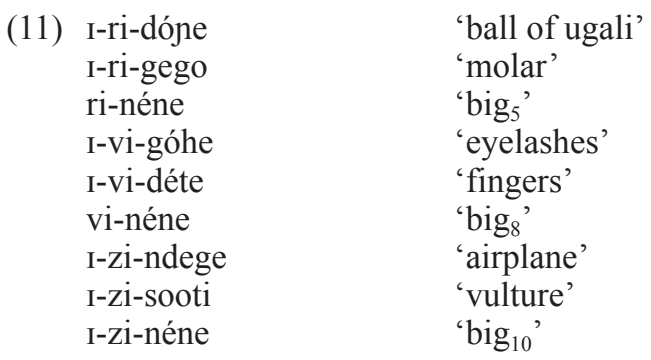

The target vowel also may not be immediately preceded by a nasal consonant. ${ }^{8}$ This restriction is illustrated with three prefixes with the form /mv-/: Class 1, Class 3 and Class 16 locative.

\begin{tabular}{|c|c|}
\hline v-mu-ko & 'brother-in-law' \\
\hline ひ-mひ-déérwa & 'an only child, \\
\hline -mv-tere & 'jute mallow ${ }_{3}$ ' \\
\hline v-mu-kóóne & 'sugar cane ${ }_{3}^{\prime}$ \\
\hline mo-néne & ' $\operatorname{big}_{1,3}$ ' \\
\hline mu-doto & 'soft 1,3 ' \\
\hline mu-béde & 'in ${ }_{16}$ a ring' \\
\hline mo-ke-reenge & 'in ${ }_{16}$ a leg' \\
\hline
\end{tabular}

The Cl. 4 prefix /mi-/ likewise does not undergo vowel harmony, both because of its vowel and because of the preceding consonant.

$\begin{array}{ll}\text { (13) I-mí-'tééndé } & \text { 'plant sp.' } \\ \text { I-mi-kóno } & \text { 'hands' } \\ \text { mi-néne } & \text { 'big }{ }_{4} \text { ' }\end{array}$

Vowel harmony iterates through a sequence of prefix vowels. The following examples illustrate harmony applying to the object prefixes for Classes 9 (/gI-/) and 14 $(/ \mathrm{vv} /)$, the persistive prefix /-kI-/, and the subject prefixes /ひ-/ '2s', /kU-/ '1p' and /I-/ 'Class 9'.
(14) v-kI-gI-várízaa
kv-vひ-naajáa
o-ko-vegáa
ko-ke-deekáa
o-ke-vo-deekáa
e-ke-ge-róráa
'you are still counting it,'
'we are eating it $_{14}$ '
'you are shaving us'
'we are still cooking'
'you are still cooking it $_{14}$ '
'it ${ }_{9}$ is still seeing it,

If any syllable intervenes between the trigger with a mid vowel and a target with a lax high vowel, where that syllable cannot undergo harmony, then harmony is blocked at that point. For example, the object prefixes /-mu-/ 'Class 1', /-va-/ 'Class 2', and the tense prefixes /-ra-/ 'immediate future', /-ri-/ 'indefinite future' prevent application of harmony to any prefix preceding them.

8 No prefixes contain $/ \mathrm{n} /$
(15) ku-ra-déeka

*ko-ra-déeka

v-mひ-teméráa

*o-mひ-teméráa

I-ri-ke-rééta

ku-kI-va-deekéráa 'we are still cooking for them ${ }_{2}$ '

'we will cook'

'you are chopping for him'

'it, may bring it,'

The rule is also blocked when a potential target vowel does not undergo harmony, which is possible because harmony is optional and thus may not apply at all, or may apply to only the rightmost potential target, or the rightmost two potential targets. A vowel cannot be skipped over.

(16) kv-kI-gI-temáa 'we are still chopping it'

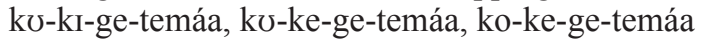
*ko-kI-gI-temáa, *ku-ke-gI-temáa,

*ko-kI-ge-temáa

\subsection{Geminate blockage}

The rules creating geminates must apply before vowel harmony does, because when a geminate consonant is created by the former rules, harmony cannot propagate across the geminate, even when harmony is possible in the same unreduced morpheme sequence.

$$
\begin{aligned}
& \text { ko-ró-deeka 'to cook it } 11 \text { ' } \\
& \text { ku-d́d-deeka, *ko-d́-deeka 'you are still receiving } \\
& \text { o-ke-ro-jooráa } \\
& \text { ช-kI-ńn-nooráa, } \\
& \text { *o-ke-jn-nooráa o-vo-vooráa 'you are saying it } 14 \text { ' } \\
& \text { ひ-v-vooráa, *o-v-vooráa }
\end{aligned}
$$

The problem which needs to be solved in a formal analysis of these rules is: how is geminate blockage represented in the rule system?

\section{THE RULES}

Having presented the main facts, we turn to a formal analysis of the rules.

\subsection{The reduction and gemination rules}

The first question is how gemination is formalized. A particular challenge to answering this is the fact that phonological theory has largely disregarded details of explicit rule formalization, ever since the advent of autosegmental phonology.

The simplest statement of the process begins with deletion of a vowel in the relevant environment. The vowel which deletes is underlyingly [+high], alternatively [-low]. ${ }^{9}$ That vowel is followed by a coronal noncontinuant, and it is preceded by $/ \mathrm{r} /$. The only coronal consonants which appear in the relevant context are $/ \mathrm{r} /$, $/ \mathrm{t} /$ and $/ \mathrm{z} /$. There is no reduction after $/ \mathrm{t} /$, as shown by the 


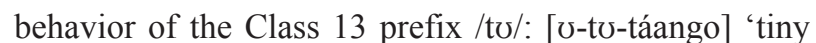

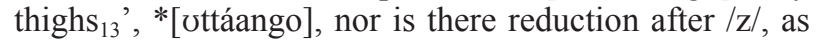
shown by the Class 10 prefix /zi/: [I-zi-táábv] 'troubles', *[Iztáábo], *[istáábo], *[ittáábv]. The distinction between $/ \mathrm{r} /$ versus $/ \mathrm{z} /$ and $/ \mathrm{t} / \mathrm{can}$ be expressed in the rule by specifying that the preceding consonant must be [+sonorant]. There is no reduction before coronals in the prefixes /vo-/, /vi-/, /gI-/, /go-/, but this is already predicted by the requirement that the preceding consonant be [+sonorant] for there to be deletion.

There are, however, other prefixes with sonorants before a high vowel: Class $4 / \mathrm{mi}-/$ and Class 1, 3, $16 / \mathrm{mv}-/$. Prefixes of the form $/ \mathrm{mu}-/$ do actually undergo optional reduction before any consonant, by a separate rule. ${ }^{10}$

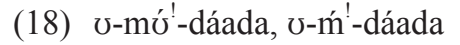
U-mひ-róombi, $\mho$-m̀-róombi ひ-mớ -stáári, $\mho-m$ '-stáári

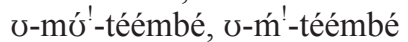

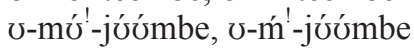

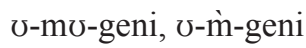

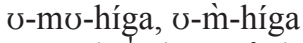

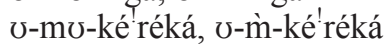

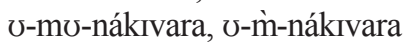

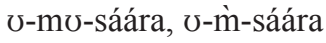
v-mu-tere, $\mho$-̀̀-tere

'wallet'
'builder'
'line'
'plant sp.'
'member of
parliament'
'guest'
'year'
'potash'
'non-Logoori'
'tree'
'jute mallow'

The pattern of reduction in $/ \mathrm{mo} /$ is sufficiently different from that of $/ \mathrm{ri}$, ro/ that a separate rule is needed to account for the facts of $/ \mathrm{mo} /$, and such examples can be disregarded.

The prefix $/ \mathrm{mi} /$ also reduces to moraic $/ \mathrm{m} /$ before a labial, but does so only before a labial - it does so before any labial.
(19) I-mi-féréji, I-m̀-féréji
I-mi-vaango, I-m̀-baango
I-mi-páángo, I-m̀-páángo
I-mi-mósi, I-m̀-mósi
I-mí'-dáada
I-mi'-stáári
I-mi-híga
I-mi-sáára
I-mi-tere

flanked by homorganic consonants, under the minimalist assumptions about rule-formulation of FP. ${ }^{11}$

Accordingly, our first reduction rule deletes a high vowel after a coronal sonorant before a coronal non-continuant.

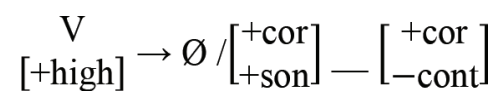

On the typical nonlinear theoretical assumption that the rule deletes only segmental content, and prosodic structure is retained and minimally restructured, applying this segmental rule to /kv-rú-taaga/ 'to plant it $_{11}$ ' will yield kortaaga. In general, $/ \mathrm{rVC} / \rightarrow r C$, where $r$ is moraic (syllabic). The general non-linear account of compensatory lengthening is that when the vowel segment deletes, its mora is transferred to the preceding consonant / $\mathrm{r}$ /, making it moraic. An additional rule is needed to derive the surface form [kǔttaaga]. Obviously, in the SPE theory of representation, deletion of the vowel and transfer of tone to the preceding consonant requires more complex mechanisms, whose deficiencies are well known.

Deletion of a high vowel between instances of $v$ is governed by a separate rule. Bearing in mind the fact that high vowels also delete after $/ \mathrm{m} /$ before any labial, it is not necessary to limit the preceding consonant to $/ \mathrm{v} /$. However, since deletion after $/ \mathrm{v} /$ only takes place before $/ \mathrm{v} /$ and not before $/ \mathrm{m}, \mathrm{p}, \mathrm{f} /$, the righthand context must be specifically restricted to $/ \mathrm{v} /$, as stated in the following rule.

$$
\underset{[+ \text { high }]}{\mathrm{V}} \rightarrow \varnothing /[+ \text { labial }]-\left[\begin{array}{c}
\text { +labial } \\
+ \text { voice } \\
+ \text { cont }
\end{array}\right]
$$

Applying this rule to /ku-vú-variza/, with the previously-mentioned assumption of prosody-preservation, we derive [kov́variza]. Both of these vowel deletion rules are optional.

To complete the derivation of coronal geminates, we require a further assimilation rule. There are no sequences of $[\mathrm{rC}]$ in the language, ${ }^{12}$ and some rule of assimilation is both necessary (to accounts for the facts) and non-problematic. The exact form of that process is what requires discussion. Assimilation, however it is formulated, is obligatory.

One approach to this assimilation is direct feature changing, in the style of SPE assimilation: the features of $/ \mathrm{r} /$ change to copy those of the following consonant. An $S P E$-style formulation would be:

While reduction of $/ \mathrm{mi} /$ is insensitive to the manner of articulation of the following labial, reduction of $/ \mathrm{rV} /$ is sensitive to whether the following coronal is a fricative or not. This precludes collapsing all of these processes into a single generalized rule which applies to high vowels

10 Logoori contrasts syllabic versus non-syllabic preconsonantal $m$, for example [vááḿboha] 'they tied him', [váámboha] 'they tied me'. Syllabic $m$ has greater duration and bears distinctive H versus L tone. Syllabic nasals will thus be notated with grave versus acute accent.
$11 S P E$ rule theory in principle allows any conditional relation to be expressed in a single rule, but there is no evidence for such an openended theory of rules.

12 The noun 'paper', contemporarily borrowed from Swahili karatasi has a wide range of pronunciations including $I$-ká!rátáási, I-kárá dáási, ri-gáradáási, ri-káradáási, and notably I-gár dáási, ri-kár táási, which constitute the only instances of $\mathrm{rC}$ in the language. Formally speaking, this word is an exception to assimilation. 


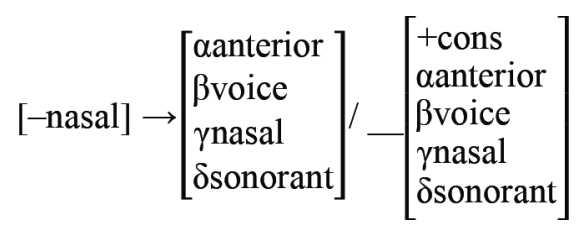

An alternative formulation which results in a sequence of adjacent identical consonants is inspired by Reiss (2003), where rules may include quantifiers, identity conditions, and fewer variables. ${ }^{13}$ The specific mode of formulation using " $=$ " is discussed in Odden (2013).

$$
[- \text { nasal }] \rightarrow[=\text { Features }] /\left[\begin{array}{c}
+ \text { cons } \\
=\text { Features }
\end{array}\right]
$$

"Features" is an abbreviation for the entire set of segmental features, that is, everything dominated by the Root node.

A transcriptionally equivalent approach assumes that a geminate consonant is a single consonant associated to a mora - this is the standard autosegmental account of geminates, as discussed in section 2.1. Such a structure is created from the intermediate representation koŕtaaga, where $r$ is a moraic consonant, by applying a rule that spreads the segmental features of a following consonant to a preceding moraic $r$, displacing the segment $r$. Here, "R" represents the root node of a segment.

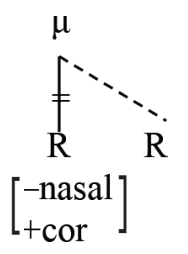

\subsection{The vowel harmony rule}

Now we turn to the formalization of harmony. The basic generalization is that a lax high vowel becomes mid when followed by a mid vowel in the next syllable. Many theoretical questions need prior resolution, such as whether the rule copies feature values from one vowel to the next, or does it expand the domain of association of the harmonizing feature. As an SPE-style copying rule, the rule could be stated roughly as follows: ${ }^{14}$

$$
\underset{[- \text { tense }]}{\mathrm{V}} \rightarrow[-\mathrm{hi}] /-\underset{[-\mathrm{hi}]}{\mathrm{V}}
$$

13 Reiss only considers identity references in segments in the context, not those involved in the structural change of a rule.

14 The exact feature structure of vowel height is not the central question. Mid vowels will be treated uniformly as [-hi], with /a/ being [+low] and lacking any specification of [hi]. Alternatively, [-hi] in all of the rule formalisms can be replaced with [+hi,-low]. See Clements \& Hume, 1995; Parkinson, 1996; Pulleyblank, 2011, among others for theoretical accounts of vowel height features. In autosegmental versions of the rule, VH stands for Vowel Height.
It can also be expressed as spreading of the relevant feature:<smiles>[AlH2][AlH2]</smiles>

Since the vowels in question are never segmentally adjacent (see [okevodeekáa] 'you are still cooking it ${ }_{14}$ ' from / vkivひdeekáa/), and since two consonants may

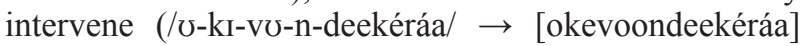
'you are still cooking it ${ }_{14}$ for me'), some account of intervening consonants is necessary. SPE's whole-segment based approach to the matter is that one encodes intervening consonants with an abbreviatory device, $\mathrm{C}_{0}$, standing for an infinite sequence of consonants, thus:

$$
\underset{\lceil- \text { tense }\rceil}{\mathrm{V}} \rightarrow[- \text { hi }] /-\mathrm{C}_{0} \underset{\lceil- \text { high }\rceil}{\mathrm{V}}
$$

The standard autosegmental approach to segment skipping is based on the premise that not all segments bear specifications for all features (as they do in $S P E$ theory), and in particular, consonantal place of articulation features are typically drawn from a distinct set of features, so consonants are not necessarily present on those tiers occupied by vowel features. Under that presumption, the autosegmental spreading rule (26) is correct as it stands (as an expression of the generalization that vowel height spreads from vowel to vowel), in that the vowels involved are literally adjacent at the level of the involved feature node.

One further fact needs to be encoded in the harmony rule, which is that if the consonant preceding the target is nasal, vowel harmony does not apply. Formally expressing this generalization poses a significant challenge. It is not required that there be an oral consonant before the target - harmony targets the initial vowel in [okevoondeekéráa], where the target is not preceded by a consonant at all. The rule cannot be stated as requiring a preceding [-nasal] segment, since vowel harmony applies even when no consonant precedes. The condition pertaining to nasals must also be framed in terms of immediate precedence: see for example /n-kI-vひ-deekáa/ $\rightarrow$ [ngevodeekáa] 'I am still cooking $\mathrm{it}_{14}$ ', where a non-adjacent nasal does not block the rule.

The question of how to properly state a blocking condition is discussed - and not resolved - in Odden (2011b). Braces may be employed to either require a preceding oral consonant, or a word boundary.

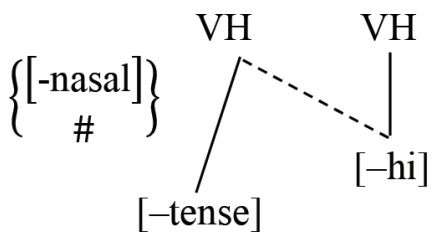


If the complement notation is indeed legitimate, the rule may be formulated as follows.

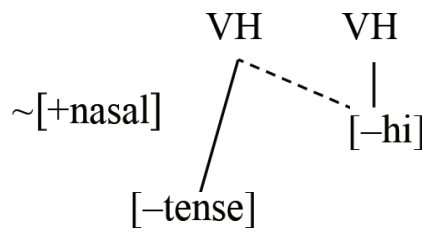

Since there is no clear empirical or theoretical argument favoring one of these two accounts, the blocking account will tentatively be adopted. We will have occasion to contemplate further use of the complement notation.

\subsection{Encoding geminate blockage}

We still require some account of the fact that geminates block vowel harmony, which is not yet encoded in the rule.

One way to encode geminate blockage is via an explicit condition in the rule, disallowing geminates between target and trigger vowels. Owing to the highly restricted set of consonant sequences in the language, it suffices to distinguish [nd] and [mb] (which may intervene) from other homorganic consonant sequences (which block harmony). Here is a first attempt at such a rule.

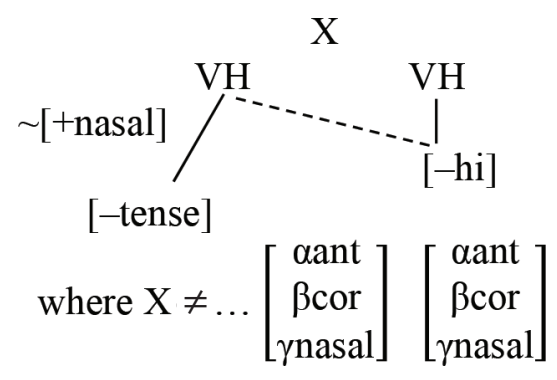

Geminates can be identified by virtue of the fact that they are homorganic sequences having the same value for [nasal], as opposed to [mb] and [nd] where the consonants have different values for nasal. An alternative statement could informally relate blockage to the OCP - we might instead say "where X contains no violation of the OCP".

The approach embodied in (30) faces two kinds of problems. The first question is whether the rule mechanisms posited for (30) are valid. Are general variables such as $\mathrm{X}$ a valid device in rule theory - do rules actually say "If $X=\ldots$ "? Related to that is the question whether blocking conditions are legitimate: " $\mathrm{X} \neq \ldots$...". Are general value-variables as employed above legitimate?

Because consonant sequences in Logoori are highly limited, the required condition might be restated without the implied negative existential ("there does not exist a sequence such that..."). Instead we can express the condition as allowing only certain two-consonant sequences: the only $\mathrm{CC}$ sequences allowed to stand between the target and trigger vowels have a nasal as $\mathrm{C}_{1}$ and an oral obstruent as $\mathrm{C}_{2}$.
For /ひ-kI-vひ-n-deekéráa/ to be allowed to undergo vowel harmony ([okevoondeekéráa $]^{15}$ 'you are still cooking for me'), we need a rule expression that admits [nd, $\mathrm{mb}$ ] and rejects [dd, nn, vv] - a sequence of two consonants is allowed only if they disagree in nasality, that is, " $X=([$ anasal $])[-$ anasal]". Either there is only one segment between the vowels, which must be "[- - nasal]", or there can be two segments, which must disagree in nasality. In restating the blocking condition this way, we have traded in one set of problems for a different set of problems. Are parentheses a legitimate formal device? is "algebraic opposite" $(-\alpha)$ a legitimate formal device? is bare "[- - nasal]" formally interpretable?

The second and even greater formal problem with this explicit-encoding approach is that it is not even interpretable with the desired effect, regardless of the conditions on X. The problem is that " $X$ " is just hanging on a separate tier, graphically positioned between the VH nodes which are on a different tier, but with no formal provision that $\mathrm{X}$ is "between" the target and trigger. The mere presence of a geminate in a word does not block harmony (cf. /ru-rakú-reeterwa/ $\rightarrow$ [llakóreeterwa] 'it ${ }_{11}$ will be brought for

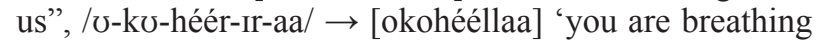
on us'): there is blockage only when the geminate comes between the target and trigger vowels.

The variable $\mathrm{X}$ does not refer to a property of $\mathrm{VH}$ nodes, it refers to nasal nodes (at best) or a disparate array of nodes covering Place and the feature nasal. The apparently-blocking features do not "stand between" the VH nodes. An element on one tier neither precedes nor follows an element on another tier: precedence is defined only within a tier. The rule prohibits the presence of a substring ("X") which contains a geminate, but nothing in (30) limits that condition to "between the VH nodes". The only thing with a precedence relation to $\mathrm{VH}$ is another instance of $\mathrm{VH}$. The rule specification must be expanded to include reference to root nodes, via which a geminate could be said to stand between the VH nodes - by reference to the root nodes.

The rule may apply between vowels whose root nodes are not separated by a geminate, as stated in the following rule.

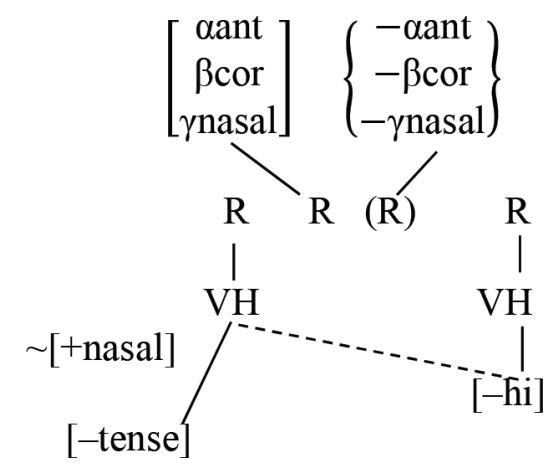

15 Within words, vowels always lengthen before onset NC clusters, possibly because the preconsonantal nasal is underlyingly moraic and transfers its mora to the preceding vowel. 
Again, the complexity of the rule and the otherwise unnecessary formal devices (value variables, disjunctive braces, parentheses) motivate the search for a simpler analysis.

A different approach to this problem is proposed in Odden (1994), where rule statements may be extended by an appeal to adjacency parameters. The proposal is that one of two requirements can be imposed on a rule, namely syllable adjacency (where the target and trigger segments in a rule must be in adjacent syllables) and root adjacency (where the root nodes of the target and trigger segments must be adjacent). The original proposal only includes "root" and "syllable" as elements whose adjacency can be required, but there is no principled impediment to extending the set of adjacency conditions available to rules, to allow for "moraic adjacency". Accordingly, harmony could be limited to only apply to Vowel Height nodes which are dominated by adjacent moras. In pursuing this approach, we will see that the concept of "adjacency parameter" is entirely superfluous, and the effect follows from stating the rule correctly.

Consider the input / $\mho-k I-v \mho-n-d e e k e ́ r a ́ a /$ to vowel harmony, in the case of [okevoondeekéráa] 'you are still cooking for me', with two onset consonants intervening between the target and trigger vowels. No mora stands between $\mu_{2}$ and $\mu_{3}$, which are adjacent moras of $\mathrm{VH}_{1}$ and $\mathrm{VH}_{2}{ }^{16}{ }^{16}$ We can say that the $\mathrm{VH}$ nodes in (32) are moraically adjacent since the last mora linked to $\mathrm{VH}_{1}$ is adjacent to the first mora linked to $\mathrm{VH}_{2}$.

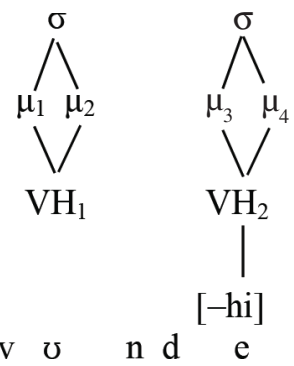

Compare this to the representation of [चkıddeekéráa]

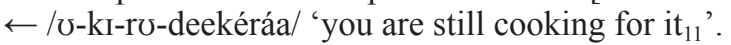

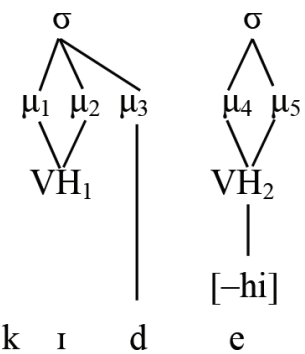

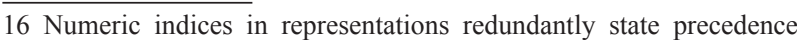
relations, standardly encoded by the left-to-right presentation of symbols on a line: they are there only to make it possible to understand statements about representations, such as when " $\mu_{3}$ stands between $\mu_{2}$ and $\mu_{4}$."
In this structure, $\mathrm{VH}_{1}$ and $\mathrm{VH}_{2}$ are not adjacent with respect to moras: $\mu_{3}$ which does not dominate $\mathrm{VH}$ stands between $\mu_{2}$ and $\mu_{4}$. Geminate blockage can thus be accomplished by imposing a moraic adjacency condition on the VH nodes involved in the rule. This may seem to support expanding rule notation to include adjacency conditions in the set of elements defining a rule.

Suppose, however, that we simply restate the autosegmental vowel harmony rule (29) as (34), adding mention of dominating moras:

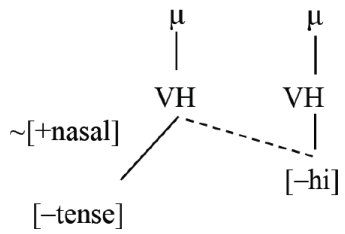

To apply this (or any rule), we require a rule-to-string matching algorithm. Such algorithms are available for $S P E$-theoretic rules and representations, see Chomsky \& Halle (1968, pp. 390-399), Howard (1972, pp. 30-35). The details of string-to-rule matching have been glossed over in research within the autosegmental tradition, but no significant changes to the "heart" of the algorithm are necessitated by nonlinear representations.

In $S P E$-style rule formulation, a rule contains a description of the input sequences that are to be changed. That description is a set of representational objects ("units" in $S P E$ terminology, i.e. classes of segments and boundaries), and relations between those objects (precedence being the only applicable relation in SPE theory). If an $S P E$-style rule states:

$$
\left[\begin{array}{c}
+ \text { cor } \\
+ \text { voice }
\end{array}\right] \rightarrow[+ \text { cont }] /-\left[\begin{array}{c}
- \text { cons } \\
- \text { nas }
\end{array}\right]\left[\begin{array}{c}
- \text { son } \\
+ \text { voice }
\end{array}\right]
$$

The rule will change / dig/ to [ðig], because a threesegment sequence is present in $/ \mathrm{dig} /, \mathrm{seg}_{1}$ in the representational sequence i.e. /d/ is described by $\operatorname{seg}_{1}$ in the rule string, likewise $\operatorname{seg}_{2}$ and $\operatorname{seg}_{3}$ of the rule and representational strings match, and the relational requirements of the segments required by the rule are satisfied $-\mathrm{seg}_{1}$ immediately precedes $\mathrm{seg}_{2}$, which immediately precedes $\mathrm{seg}_{3}$. Autosegmental phonology simply adds to this that the elements specified in a rule may either be in an immediate precedence or a dominance relation.

The description in (34) requires that some $\mathrm{VH}$ node $_{1}$ immediately precedes a $\mathrm{VH}$ node 2 , that $\mathrm{VH}_{1}$ must dominate [-tense], and $\mathrm{VH}_{2}$ must dominate [-hi]. Moreover, morae must dominate those $\mathrm{VH}$ nodes, and the first $\mu$ immediately precedes the second $\mu$. In other words, the fact of requiring that there be moras dominating the $\mathrm{VH}$ nodes, as specified in (34), directly yields the result that no mora can be skipped over. An expression that includes " $\mu \mu$ ", that is, two moras which are written next to each other, literally means that the first $\mu$ immediately precedes the second $\mu$. A literal interpretation of the rule 
requirements reduces the moraic adjacency requirement to being a consequence of how the rule is stated. In representation (33), an extra mora (the one dominating the consonant) stands between the moras linked to VH nodes required by the rule.

More generally, adjacency parameters are conceptually superfluous. There is no need to add any such concept to the theory of rules, since the desired result follows from the autosegmental theory of rule-to-string matching. In $S P E$ rule theory, it was unnecessary to independently state that a rule "V $\rightarrow \varnothing / C V$ " does not apply to /VCCV/, because /VCCV/ simply does not match what is required by the rule, VCV. The structure (33) likewise does not fulfill the requirements of (34), which demands a structure with $\mathrm{VH}_{1}, \mathrm{VH}_{2}, \mu_{1}$ and $\mu_{2}$, dominance of $\mathrm{VH}_{1}$ by $\mu_{1}$, dominance of $\mathrm{VH}_{2}$ by $\mu_{2}$, and immediately precedence between $\mathrm{VH}_{1}$ and $\mathrm{VH}_{2}, \mu_{1}$ and $\mu_{2}$.

The formalization of vowel harmony is not yet complete, since blockage by a preceding nasal is not yet properly integrated into the analysis. The version in (34) suffers from the "floating blocker" defect that (30) was criticized for: nothing relates the "not a nasal" requirement to any segment that immediately precedes the target segment. The remedy is quite straightforward - the target segment (root node) may not be immediately preceded by a nasal segment, as stated in

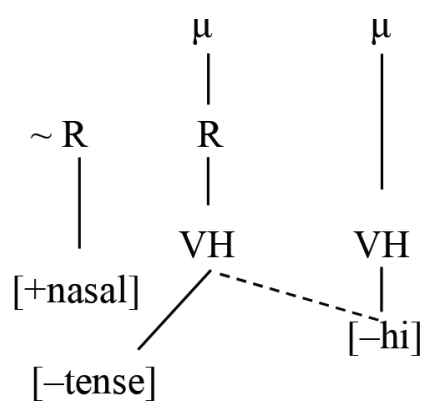

This final correction has an interesting consequence for the question of adjacency parameters in rule formalism: there are two different adjacency conditions in Logoori harmony. One is that the target segment must not be immediately preceded, at the level of the segment, by a nasal. The other is that the mora which dominates the target $\mathrm{VH}$ node must also immediately precede the mora which dominates the trigger $\mathrm{VH}$ node. In other words, both root adjacency and moraic adjacency conditions are active in the rule - meaning that "root" versus "mora" is not a parameter which is set for the rule as a whole. This is explained in the present theory by the exact formulation of the rule. If the fact of the language were that the target and trigger must be segmentally adjacent, that would be expressed by adding to (36) a specification of a root node dominating the trigger $\mathrm{VH}$ node.

A final theoretical matter is raised by the fact that the target and trigger vowels are specified differently (36), but there is no corresponding difference in the feature composition of those vowels - (36) does not mean "as long as the VH node of the following vowel is immediately dominated by a mora". It has been implicitly assumed here that association lines in rules represent dominance relations, so the condition on the rightmost element is that a mora dominates a $\mathrm{VH}$ node. This does not mean that $\mu$ immediately dominates $\mathrm{VH}$ with no intervening structure.

It is not clear that there is a motivated distinction in rule formalism between the requirement of domination versus immediate domination. There has been a widely accepted, and possibly incorrect, premise that the hierarchy of featural nodes in a representational tree is fixed. Given that premise, including a specification "immediately dominated" in rule formalism would be unnecessary. However, some theories of representation, such as Unified Features Theory, do allow contrastive domination relations. There is, therefore, the potential for a problem with the present proposal, in case it becomes necessary to notate immediate domination as distinct from general domination - this is clearly a matter for future research in the theory of representations and rule formalism.

\section{CONCLUSIONS}

The central characteristic of generative grammar, as a theory of the language faculty, is that it is supposed to be an explicit and formalizable theory of grammatical computations. Developing such a theory is a Herculean undertaking, one that depends on an ever-expanding foundation of knowledge of language facts and continuing theoretical refinements regarding this computational faculty. After an initial period of intensive attention to the formal nature of computations in the $S P E$ era, phonological research switched focus for a long time to questions about the representations which rules operate on. While it is obvious that the rules can't be right if the representations are wrong, even if you have the representations right, the form of a rule does not follow automatically. Much greater focus needs to be placed on the nature of the formal computations, in light of our expanded knowledge of representations.

\section{ACKNOWLEDGEMENTS}

I thank Editon Mulera for providing these data on Logoori. Research on Logoori was supported by NSF Grant BCS-1355750 to Michael R. Marlo and the University of Missouri.

\section{REFERENCES}

Baković, E. (2005). Antigemination, assimilation and the determination of identity. Phonology, 22, 279-315. http://dx.doi. org/10.1017/S0952675705000631

Butler, L. (2005). Exceptional blocking of Yucatec Maya vowel harmony. LSO Working Papers in Linguistics, 5: Proceedings of the Workshop in General Linguistics 2005 (pp. 25-39). University of Wisconsin, Madison: Linguistics Students Organization.

Chomsky, N. \& Halle, M. (1968). The Sound Pattern of English. New York: Harper and Row.

Clements, G. N. \& Hume, E. (1995). The internal organization of speech sounds. In J. Goldsmith (Ed.), Handbook of Phonological Theory (pp. 245-306). Oxford: Basil Blackwell. 
Clements, G. N. \& Keyser, S. J. (1983). CV Phonology: A Generative Theory of the Syllable. Cambridge, MA: MIT Press.

Davis, S. (1994). Geminate consonants in moraic phonology. West Coast Conference on Formal Linguistics, 13, 32-45.

Davis, S. (2011). Geminates. In M. van Oostendorp, C. J. Ewen, E. Hume \& K. Rice (Eds.), The Blackwell Companion to Phonology (pp. 873-897). Malden, MA \& Oxford: WileyBlackwell. http://dx.doi.org/10.1002/9781444335262. wbctp0037

Hayes, B. (1989). Compensatory lengthening in moraic phonology. Linguistic Inquiry, 20, 253-306.

Howard, I. (1972). A Directional Theory of Rule Application in Phonology. Doctoral Dissertation, MIT: Cambridge.

Kenstowicz, M. \& Pyle, C. (1973). On the phonological integrity of geminate clusters. In M. Kenstowicz \& C. Kisseberth (Eds.), Issues in Phonological Theory (pp. 27-43). Mouton: The Hague. http://dx.doi.org/ 10.1515/9783110905137.27

Krämer, M. (n.d.). A correspondence approach to vowel harmony and disharmony. Rutgers Optimality Archives (ROA) 293. http://roa.rutgers.edu/files/293-0199/roa-293kraemer-4.pdf

Krämer, M. (2001). Yucatec Maya vowel alternations - Harmony as syntagmatic identity. Zeitschrift für Sprachwissenschaft, 20, 175-217. http://dx.doi.org/10.1515/zfsw.2001.20.2.175

Leben, W. (1980). A metrical analysis of length. Linguistic Inquiry, 11, 497-509.

McCarthy, J. (1979). Formal Problems in Semitic Phonology and Morphology. Doctoral Dissertation, MIT. http://dx.doi. org/10.4324/9780429468629

McCarthy, J. (1986). OCP Effects: Gemination and antigemination. Linguistic Inquiry, 17, 207-263.

McCarthy, J. (1988). Feature geometry and dependency: A review. Phonetica, 45, 84-108. http://dx.doi.org/10.1159/ 000261820
McCawley, J. (1974). Review of The Sound Pattern of English by Noam A. Chomsky and Morris Halle. International Journal of American Linguistics, 40, 50-88.

Morén, B. (1999). Distinctiveness, Coercion and Sonority: A Unified Theory of Weight. Doctoral Dissertation, University of Maryland at College Park.

Odden, D. (1988). Anti Antigemination and the OCP. Linguistic Inquiry, 19, 451-475.

Odden, D. (1994). Adjacency parameters in phonology. Language, 70, 289-330. http://dx.doi.org/10.2307/415830

Odden, D. (2011a). The representation of vowel length. In M. van Oostendorp, C. J. Ewen, E. Hume \& K. Rice (Eds.), The Blackwell Companion to Phonology (pp. 465-490). Malden, MA \& Oxford: Wiley-Blackwell. http://dx.doi. org/10.1002/9781444335262.wbctp0020

Odden, D. (2011b). Rules v constraints. In J. Goldsmith et al. (Eds.), Handbook of Phonological Theory, vol 2 (pp. 1-39). Malden, MA \& Oxford: Wiley-Blackwell. http://dx.doi. org/10.1002/9781444343069.ch1

Odden, D. (2013). Formal phonology. In S. Blaho, M. Krämer \& B. Morén-Duolljá (Eds.), A Festschrift on the Occasion of X Years of CASTL Phonology and Curt Rice's $L^{\text {th }}$ Birthday. Nordlyd, 40.1, 249-273. http://dx.doi. org/10.7557/12.2476

Parkinson, F. (1996). The Representation of Vowel Height in Phonology. Doctoral Dissertation, Ohio State University.

Pulleyblank, D. (2011). Vowel height. In M. van Oostendorp, C. J. Ewen, E. Hume \& K. Rice (Eds.), The Blackwell Companion to Phonology (pp. 491-518). Malden, MA \& Oxford: Wiley-Blackwell.

Pyle, C. (1971). On the Treatment of Length in Generative Phonology. Doctoral Dissertation, University of Illinois.

Reiss, C. (2003). Quantification in structural descriptions: Attested and unattested patterns. The Linguistic Review, 20, 305-338. http://dx.doi.org/10.1515/tlir.2003.012 